\title{
PROPERTIES AND MICROSTRUCTURE OF CEMENT PASTE INCLUDING RECYCLED CONCRETE POWDER
}

\author{
JAROslaV TOPIČ* ${ }^{*}$ ZDEnĚK PROŠEK \\ Czech Technical University in Prague, Faculty of Civil Engineering, Thákurova 7, 16629 Praha 6, Czech \\ Republic \\ * corresponding author: jaroslav.topic@fsv.cvut.cz
}

\begin{abstract}
The disposal and further recycling of concrete is being investigated worldwide, because the issue of complete recycling has not yet been fully resolved. A fundamental difficulty faced by researchers is the reuse of the recycled concrete fines which are very small $(<1 \mathrm{~mm})$. Currently, full recycling of such waste fine fractions is highly energy intensive and resulting in production of $\mathrm{CO}_{2}$. Because of this, the only recycling methods that can be considered as sustainable and environmentally friendly are those which involve recycled concrete powder (RCP) in its raw form. This article investigates the performance of RCP with the grain size $<0.25 \mathrm{~mm}$ as a potential binder replacement, and also as a microfiller in cement-based composites. Here, the RCP properties are assessed, including how mechanical properties and the microstructure are influenced by increasing the amount of the RCP in a cement paste $(\leq 25 \mathrm{wt} \%)$.
\end{abstract}

KEYWORDS: recycled concrete; recycled concrete powder; recycled concrete fines; mechanical properties; cement replacement.

\section{INTRODUCTION}

The disposal and further recycling of concrete is being investigated worldwide, because the issue of complete recycling has not yet been fully resolved [1]. Because concrete consists mostly of aggregates, current research is primarily focused on how to process and add coarse or fine recycled aggregates to new concrete and mortar mixtures $[2] 6$. However, reuse of the fine powder $(<1 \mathrm{~mm}$; largely consisting of a cement paste) produced during the recycling process is still complicated and often expensive. The research presented here investigates how recycled concrete powder (RCP) modified by a high-speed mill (grain size $<0.25 \mathrm{~mm}$ ) performs as a potential binder replacement, and also as a microfiller in cement-based composites.

Concrete is composed of 65 to $70 \%$ coarse and fine aggregates, with the remainder consisting of a cement paste [7]. In recycled concrete aggregates, the part containing the hydrated cement paste causes water absorption and thus can be problematic 8 . The fine fraction of recycled concrete is largely composed of a hardened cement paste, the amount of which depends on the used recycling technology. Additional RCP processing stages (e.g., crushing or grinding) can break grains down to a finer level, to a point at which water absorption no longer plays a significant role. Such RCP modification is conducted according to what specific purpose the material must fulfill. This paper discusses the RCP produced from recycled concrete that serves as a partial binder replacement or as a raw material for cement production.

\subsection{THE RCB AS A BINDER}

When reintroducing concrete powder into a mixture, clinker must be recreated with the same conventional burning process as for Portland cement clinker in a rotary kiln [1, 9]. This process requires large amounts of energy and produces high $\mathrm{CO}_{2}$ release, although less than in the case of conventional cement clinker.

Hydrated cement paste can be dehydrated with a heat treatment. Shui et al. [10] investigated this and observed that hardened cement paste treated at $500{ }^{\circ} \mathrm{C}$ is composed mainly of dehydrated C-S-H gel, $\mathrm{CaO}$, and part of the original calcium hydroxide $\left(\mathrm{CaOH}_{2}\right)$. After mixing with water, hydration products, such as C-S-H gel, ettringite and $\mathrm{CaOH}_{2}$ were re-established. Shui et al. [10 12] have demonstrated that dehydrated cement paste is capable of recreating the original hydration products upon contact with water, showing that the mechanical properties of rehydrated cement paste depend primarily on the temperature at which dehydration proceeds and also that the rehydration process can create the alkaline environment that is necessary for recreating fly ash [12]. CaO, produced by the decomposition of $\mathrm{CaCO}_{3}$ and $\mathrm{CaOH}_{2}$, can react with water and recreates $\mathrm{CaOH}_{2}$ and eventually the C-S-H gel with the presence of other compounds. This rehydration process is very similar to the Portland cement hydration; non-hydrated cement grains, which were contained in the cement paste before heat treatment, were also found to react after a contact with water.

Florea et al. [13] explored the influence of dehydration on recycling the concrete powder at different 
temperatures and possible applications for mortar mixtures, concluding that the very fine fraction of recycled concrete treated at $800{ }^{\circ} \mathrm{C}$ can be used to replace $20 \mathrm{wt} \%$ of Portland cement CEM I 42.5 in mortars without significant loss of strength, equivalent to replacing the cement with fly ash. The fine fraction of recycled concrete treated at $500{ }^{\circ} \mathrm{C}$ was not so efficient and $20 \mathrm{wt} \%$ replacement of cement led to a significant decrease in the mortar strength. Pozzolanic activity was observed at both temperatures when the fine fraction was combined with ground granulated slag. When replacing $10 \mathrm{wt} \%$ of mixed cement (containing $70 \%$ slag) with a heat-treated concrete powder, the strength of the mortar cured for 28 days improved by 15 to $20 \%$, probably due to a high lime content. Most of the samples containing the RCP had a higher compressive strength than the observed reference samples. These results suggest that the RCP can contribute to the enhancement of the mechanical properties in mixtures, which, apart from binding constituents, may also function as a filler.

Schoon et al. [14, 15] explored the possibility of using the very fine fraction of recycled concrete as an alternative material for producing the Portland cement clinker, analyzing the RCP samples from various recycling facilities to examine whether particular production processes as well as the sources of old concrete used for obtaining the RCP had an effect on the properties of clinker. The results of this study indicated that neither process nor the source had a significant effect on the mineralogy of the resulting clinker.

Other studies [16, 17] have shown that it is possible to use the RCP as an alternative to conventional materials, primarily as a source of $\mathrm{SiO}_{2}$ and in some cases, because of high content of $\mathrm{CaO}$, as an alternative to limestone. The homogenization phase must be adjusted to the specific chemical composition of any $\mathrm{RCP}$, since homogenization directly affects the production rate, particle size, and the chemical composition of cement [14].

Gastaldi et al. [16] produced a cement clinker made by combining the RCP with limestone and schist. They concluded that the mineralogical composition and a subsequent lack of $\mathrm{C}_{3} \mathrm{~S}$ prevents the use of the $\mathrm{RCP}$ on its own, because of its inappropriate proportions of $\mathrm{CaO}$ and $\mathrm{SiO}_{2}$. Because of the high $\mathrm{SiO}_{2}$ content, it is more suitable to use it as a substitute for natural sand in cement mixtures, and any mixture for clinker should contain only 20 to $40 \%$ of the RCP. At higher levels, clinker cannot be considered to be Portland clinker but rather a supplementary cementitious material. Kwon et al. [17] confirmed these findings, suggesting that $30 \%$ of the RCP should be the limit for producing high quality clinker.

Ahmari et al. 19 developed a geopolymer based binder using the RCP, together with fly ash. As a source of silicon and calcium, the RCP, at a maximum quantity of $50 \mathrm{wt} \%$, contributes to a solid bond between the new aggregate and the binder, resulting in a greater compressive strength of the geopolymer, which is in the form of a poly-sialate-disiloxo, and therefore forms a stronger bond than a geopolymer created using fly ash alone.

\subsection{THE RCP AS A MICROFILLER AND POTENTIAL BINDER}

In mixtures based on cement, microfillers are used to displace excess water between grains of cement and aggregates. Microfiller grains are smaller than cement grains and ideally should have a spherical shape [20]. The RCP can potentially serve as a microfiller, but prior research into this topic is limited.

Kim et al. 21] investigated the properties of cement pastes and mortars by partially replacing cement with the RCP, observing a workability decrease as the RCP levels increased, with hydration delayed by almost two hours compared with reference cement. In the case of mortar containing $45 \%$ of the RCP, compressive strength decreased by $70 \%$ and water absorption increased by approximately $70 \%$. Because of this a maximum of $15 \%$ of the RCP was proposed.

Lidmila and Šeps 22 24, who used a very fine fraction of recycled concrete from old railway sleepers, concluded that reactive properties can be achieved by milling, which may expose non-hydrated grains. Because reactivity is low due to the small content of non-hydrated grains, the fine fraction could be used in larger quantities to fortify railway structure subsoils [23], or in small quantities for cementitious composite materials.

Liu et al. 25] focused on the pozzolanic properties of a hybrid powder composed of concrete and brick demolition waste which was analyzed for microstructure and chemical composition. The hybrid powder significantly influenced the microstructure of the cement paste and most of the pozzolanic activity involved particles obtained from crushed bricks. A level of approximately $30 \%$ hybrid power was recommended as a replacement for cement in concrete mixtures.

The assumption regarding exposure of non-hydrated cement grains during milling process as investigated by Lidmila and Šeps [22, 23] was used as a basis for the research described in this paper. In the first stage of the research, the potential reactivity and level of milling for the RCP were explored. RCP particle size was measured to determine if milling the RCP to a level similar to cement exposed non-hydrated grains. RCP hydration heat and mechanical properties were also measurement, in order to investigate the impact of increasing RCP levels on the properties of cement pastes.

\section{MATERIALS AND SAMPLES}

Samples used in this research were made of the RCP milled by LAVARIS Ltd. at high speed and Portland cement CEM I 42.5 (Radotín, Czech Republic). The $\mathrm{RCP}$ was obtained from the PB2 and the SB8 railway 


\begin{tabular}{lcccc}
\hline \multicolumn{1}{c}{ Mixture } & $\begin{array}{c}\text { Cement (CEM I 42.5 R) } \\
{[\mathrm{g}]}\end{array}$ & $\begin{array}{c}\text { RCP } \\
{[\mathrm{g}]}\end{array}$ & $\begin{array}{c}\text { Water/binder ratio } \\
{[-]}\end{array}$ & $\begin{array}{c}\text { Slump flow test } \\
{[\mathrm{mm}]}\end{array}$ \\
\hline CEM (ref) & 1000 & - & 0.350 & $130 \pm 5$ \\
RCP 5 (5\%) & 950 & 50 & 0.350 & $130 \pm 5$ \\
RCP 10 (10\%) & 900 & 100 & 0.354 & $130 \pm 5$ \\
RCP 15 (15\%) & 850 & 150 & 0.358 & $130 \pm 5$ \\
RCP 20 (20\%) & 800 & 200 & 0.361 & $130 \pm 5$ \\
RCP 25 (25\%) & 750 & 250 & 0.365 & $130 \pm 5$ \\
\hline
\end{tabular}

TABLE 1. Composition of tested samples.

sleepers. In the first stage of the testing, a cement paste without the RCP, the (the reference sample), was used to investigate a potential reactivity and the level of milling. Second stage samples contained a combination of $50 \%$ of cement and $50 \%$ of the RCP. Both samples had the same water-binder $(\mathrm{w} / \mathrm{b})$ ratio of 0.35 and were used for calorimetric measurement. Measurement of particle size distribution and specific surface measurements were subsequently performed on both sample types.

In the second stage, cement paste samples with varying RCP percentages were tested for their mechanical properties. Six mixtures with 0\%, 5\%, $10 \%, 15 \%$, $20 \%$ and $25 \%$ of the RCP by weight were prepared (Table 1). Because cement and the RCP behave differently when mixed with water, the $\mathrm{w} / \mathrm{b}$ ratios ranged from 0.35 (cement) to 0.365 (RCP $25 \%$ ) and varied according to the RCP levels. The unifying parameter for these mixtures was workability defined by the slump flow test. Each set contained 6 prismatic samples with dimensions of $40 \times 40 \times 160 \mathrm{~mm}$. The samples were removed from casts after 2 days and shrinkage measurements were carried out. The samples were then cured for 28 days under laboratory conditions at $21 \pm 2{ }^{\circ} \mathrm{C}$ with relative humidity $50 \pm 5 \%$.

For microscope examination, only the reference cement paste and $25 \mathrm{wt} \%$ of the RCP samples were used. The tested cylindrical specimens were $30 \mathrm{~mm}$ in diameter and $50 \mathrm{~mm}$ in length. After curing, the samples were cut into $5 \mathrm{~mm}$-thick slices using a diamond saw and polished with silicon carbide grinding papers \#300, \#500, \#1200, \#2400 and \#4000. Finally, the specimens were polished by an emulsion with $0.25 \mu \mathrm{m}$ nanodiamonds. Technical alcohol was used for cleaning samples in an ultrasonic bath in-between the individual polishing steps.

\section{Measurement methods}

Calorimetric measurements were conducted on an isothermal TAM Air calorimeter for accurate measurement of heat flow and hydration heat production. Mixtures were tested for 7 days at a constant temperature of $20^{\circ} \mathrm{C}$ and were stored in sealable plastic containers, each containing from $32 \mathrm{~g}$ to $37 \mathrm{~g}$ of mixture. Based on the weight of each sample (measured before testing) the results of the heat flow and hydra- tion heat were related to a $1 \mathrm{~g}$ of cement for a better comparison between the individual RCPs.

A slump flow control test was performed on all mixtures. The mould, in the shape of a truncated cone (base diameter $80 \mathrm{~mm}$, top diameter $70 \mathrm{~mm}, 40 \mathrm{~mm}$ high), was placed on a shaking table, filled to the brim, and compacted. After filling, the mould was removed and 20 shake cycles were performed. Two perpendicular dimensions were measured after shaking. The slump flow value was defined as an average of both measurements rounded to the closest $10 \mathrm{~mm}$.

RCP particle size distribution and determination of middle grain size were performed using the Fritsch ANALYSETTE 22 MicroTec plus laser device. A Matest E009 device was used to measure the specific surface area using the Blain method.

The length of each box in the mould was measured before the mixture was added to it and the length of samples was measured after 2 days, immediately after the removal from the casts. The resulting sample shrinkage was related to the length of $1 \mathrm{~m}$ and was only preliminary measurement carried out to verify the influence of increasing $\mathrm{w} / \mathrm{c}$ ratios for RCP samples.

Dynamic Young's modulus and shear modulus were monitored using the resonance method based on measuring the natural frequency for the prismatic $40 \times 40 \times 160 \mathrm{~mm}$ samples. The samples were supported during measurement with a soft elastic pad at nodal points. Measurements were conducted on 6 samples for each set prior to flexural and compressive strength tests. Resonance detection was performed using a Brüel \& Kjær assembly consisting of a type 3560-B-120 measurement station for recording the excitation and response signals; type 4519-003 acceleration transducers; a type 8206 impact hammer type; and a computer. This method required a knowledge of the dimensions and the weight of each sample prior to testing. Excitation and response signals were transformed from the time domain to the frequency domain using the Fast Fourier Transform (FFT). Frequency Response Function (FRF) was calculated as the ratio of the response and the excitation force in the frequency domain. The appropriate basic natural frequencies were evaluated using the FRFs after which the dynamic Young's Modulus and shear modulus were evaluated [26, 27].

Flexural and compressive strength were determined 


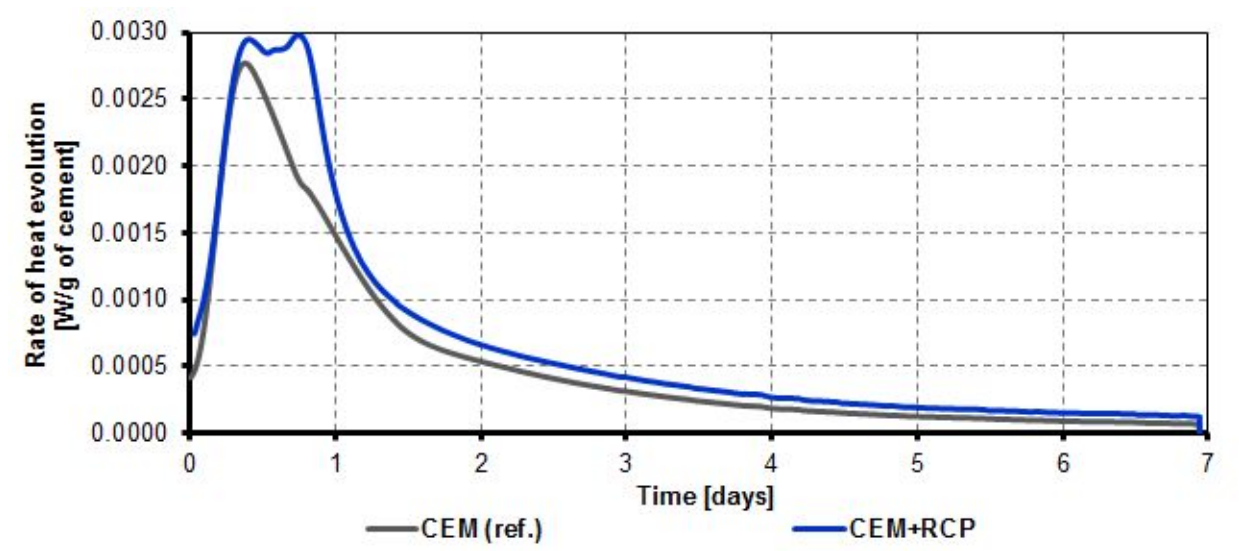

FiguRE 1. Rate of heat evolution for reference cement and cement with $50 \%$ of the RCP.

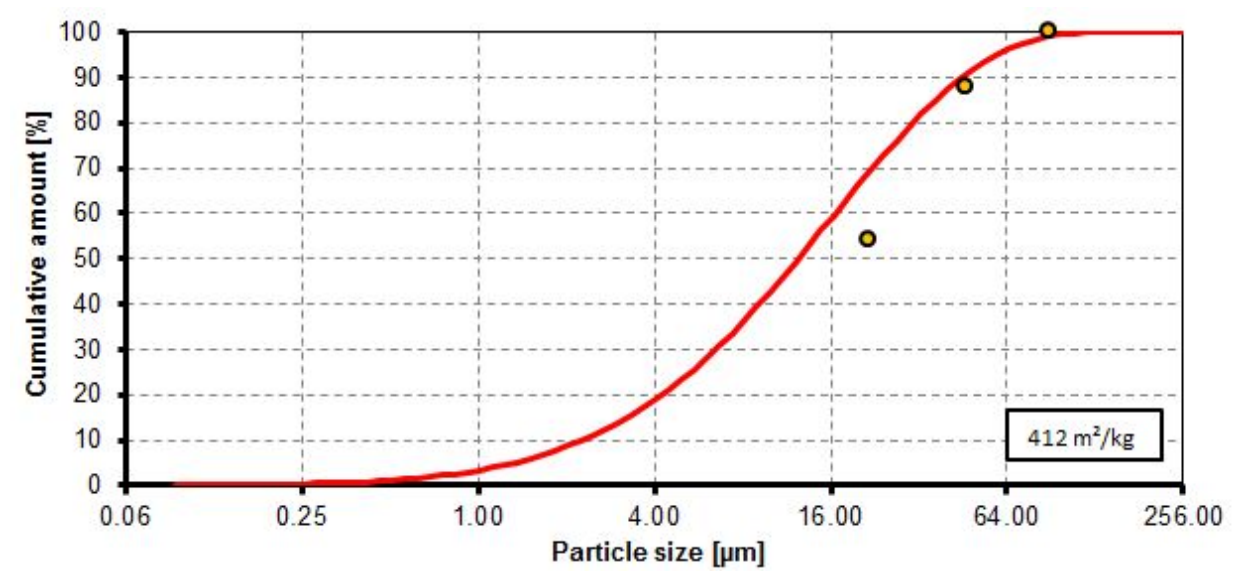

FIgURE 2. The particle size distribution and specific surface area of the RCP. Dots represent particle size distribution for CEM I $42.5 \mathrm{R}$.

on 28-day old samples using a model FP100 Heckert device. The testing was a displacement controlled at a constant rate of $0.1 \mathrm{~mm} / \mathrm{s}$ in the case of three-point bending and $0.3 \mathrm{~mm} / \mathrm{s}$ during the compression test. The distance between supports during the three-point bending test was $100 \mathrm{~mm}$. A uniaxial compressive test was performed on the broken specimen halves with effective dimensions $40 \times 40 \times \sim 80 \mathrm{~mm}$ [28, 29].

The microstructure of the composites was examined using optical and scanning electron microscopes. A Neophot 21 optical metallurgical microscope was used to obtain images at $100 \times$ magnification for the surface quality evaluation and preliminary pore distribution. A Philips XL30 ESEM-TMP FEI scanning electron microscope was used for an identification of individual phases and their levels at $100 \times$ magnification. A scanning electron microscopy (SEM) was used in BSE (backscattered electrons) mode at a low pressure (10-20 Pa) and at an accelerating voltage of $30 \mathrm{kV}$.

\section{EXPERIMENTAL RESUltS}

Figure 1 illustrates the heat evolution. By relating heat flow to a $1 \mathrm{~g}$ of cement and not an entire RCP mixture it was possible to highlight the differences in the hydration process caused by the RCP. After 8 hours, there is an obvious increase in heat flow for almost all mixtures containing the RCP versus reference cements, due to the $\mathrm{C}_{3} \mathrm{~S}$ reaction. After 19 to 26 hours, when $\mathrm{C}_{3} \mathrm{~A}$ reacts, an increase in heat flow for the RCP mixtures was also evident. After 48 hours and until the end of monitoring, $\mathrm{C}_{2} \mathrm{~S}$ reacts and the heat flow for the RCP samples was also slightly higher than in the reference samples. Hydration heat exhibited by the RCP samples during the entire 7-day measuring period was $440.105 \mathrm{~J} / \mathrm{g}$ and $352.023 \mathrm{~J} / \mathrm{g}$ for the reference cement.

Figure 2 is a particle size distribution diagram. The red line represents the RCP. $34 \%$ of the RCP particles were larger than $20 \mu \mathrm{m}$ and only $10 \%$ were larger than $45 \mu \mathrm{m}$, with the largest grain size being $130 \mu \mathrm{m}$ and an average grain size of $12 \mu \mathrm{m}$. The measured specific surface area for the RCP was $412 \mathrm{~m}^{2} / \mathrm{kg}$. The orange dots in the diagram represent CEM I $42.5 \mathrm{R}$ cement reference samples. $45 \%$ of the reference particles were larger than $20 \mu \mathrm{m}$ and $12 \%$ of the grains were larger than $45 \mu \mathrm{m}$, with the largest grain size being $90 \mu \mathrm{m}$ and the average grain size, $18 \mu \mathrm{m}$. The specific surface area of the reference cement was $351 \mathrm{~m}^{2} / \mathrm{kg}$.

Figure 3 is a shrinkage diagram. It is obvious that 


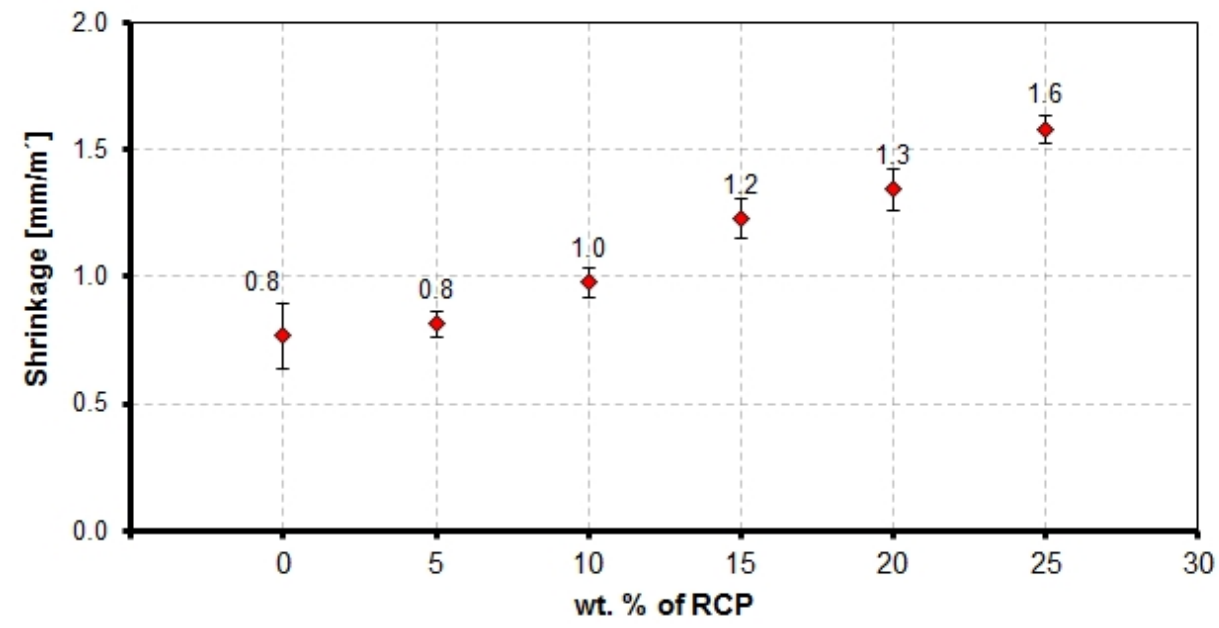

FIGURE 3. Shrinkage of samples containing increasing RCP percentages after 2 days.

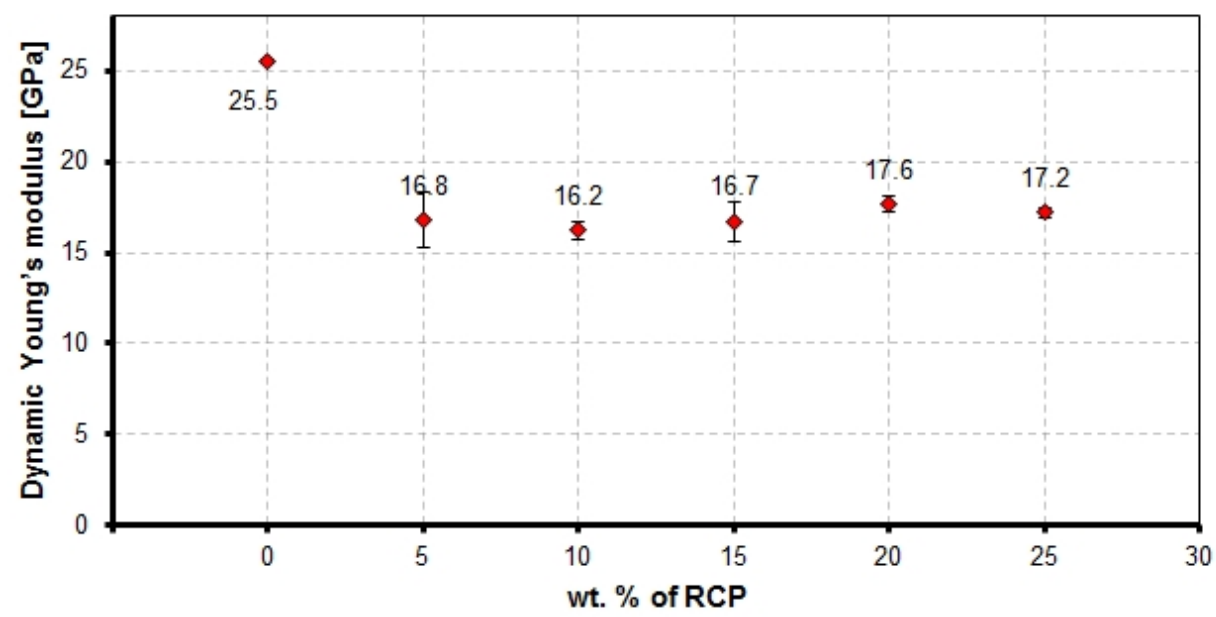

FiguRE 4. Dynamic Young's Modulus for the samples with increasing RCP percentages.

increasing levels of the RCP negatively influenced the shrinkage. There is almost no difference between reference cement and samples with $5 \mathrm{wt} \%$ of the RCP. However, between 5 and $25 \mathrm{wt} \%$ of the RCP, shrinkage increased linearly. Samples with $25 \mathrm{wt} \%$ of the $\mathrm{RCP}$ showed twice as much shrinkage as the control samples.

Figure 4 shows the dynamic Young's modulus for specimens with increasing RCP content. $5 \mathrm{wt} \%$ of the RCP samples exhibited a decrease in the dynamic Young's modulus by approximately $35 \%$ when compared with the reference samples. Higher RCP levels, up to $25 \%$, had no further impact. A similar trend was evident in the case of the dynamic shear modulus (Fig. 5). A $32 \%$ decrease of dynamic shear modulus between the reference sample and the RCP samples was observed and the percentage of the RCP had a minimal impact on dynamic shear modulus (Fig. 5).

Figure 6 shows the flexural strength for samples with increasing RCP percentages. Unexpectedly, samples with 5 wt $\%$ of the RCP exhibited higher flexural strength - approximately $7 \%$ - than the reference samples. Flexural strength was also higher for sam- ples with 15 wt\% of the RCP, approximately $25 \%$ higher than reference strength. However, increasing the RCP content to $20 \mathrm{wt} \%$ resulted in decreased flexural strength.

Figure 7 presents compression testing results, which exhibited similar patterns as the results for flexural strength. Compression strength for $5 \mathrm{wt} \%$ of the RCP samples showed an increase of almost $10 \%$ when compared to reference samples. Compression strength for $25 \mathrm{wt} \%$ of the RCP samples was still comparable to the reference samples, with a slight decrease in strength of only $4 \%$.

An optical microscope was used to take images (Figure 80 of microstructures in order to assess the surface quality and pore distribution. The replacement of the $\mathrm{RCP}$ in samples negatively affected the cohesion of mixture matrices, resulting in deterioration of the polished surface. The optical microscope images showed minimal differences in the number of pores, but, as seen in Figure 9. SEM images reveal a higher number of pores. The distribution of the various phases within the samples can also be detected in the SEM images. The RCP aggregate can be seen as the dark grey spots 


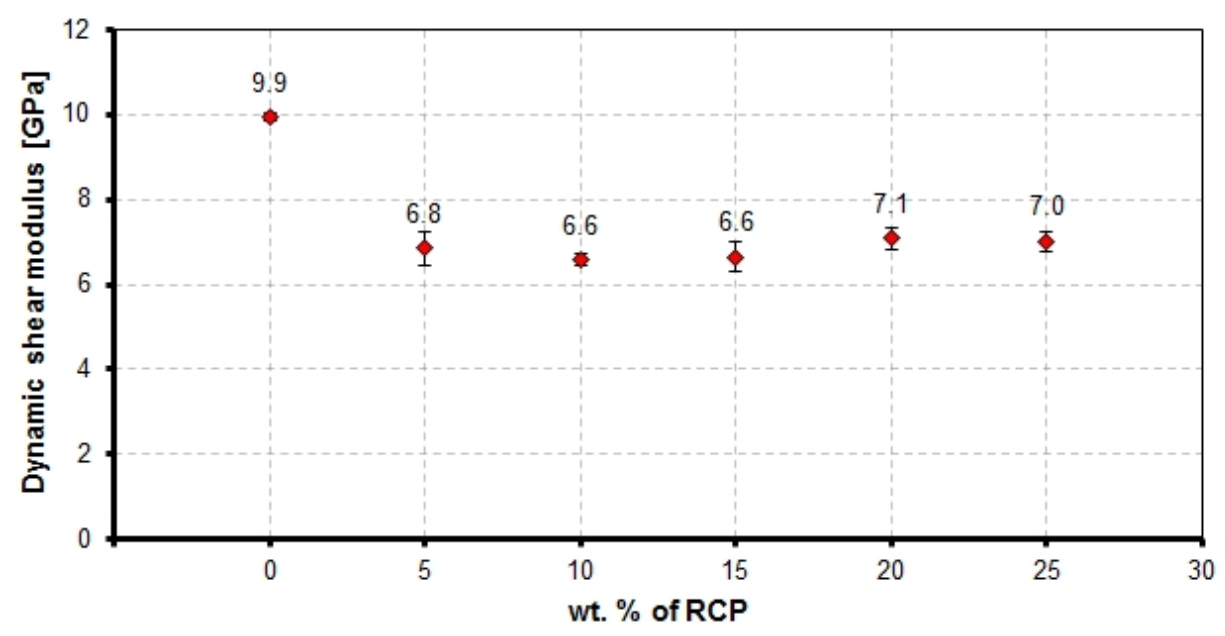

Figure 5. Dynamic shear modulus for the samples with increasing RCP percentages.

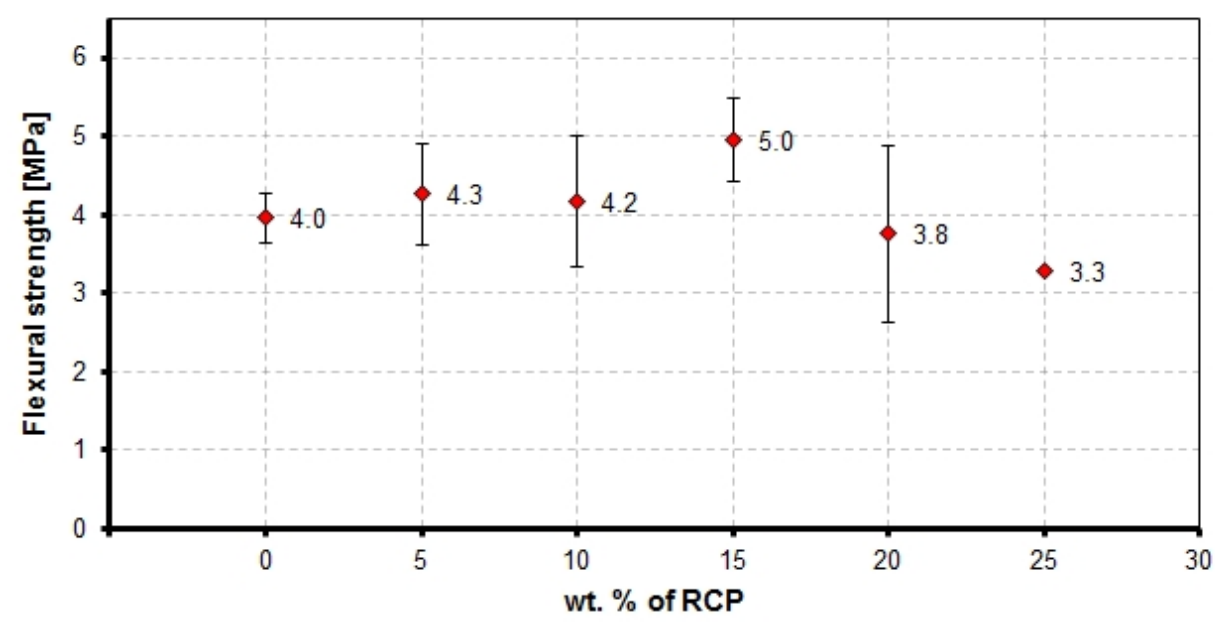

FiguRE 6. Flexural strength for samples with increasing RCP percentages.

in the RCP 25 sample. The decrease of non-hydrated cement grains (white spots) is obvious in case of RCP samples versus the reference samples. Given the ratio of cement and the RCP and the presumption that the RCP contains only a fraction of non-hydrated cement grains when compared to reference samples, an RCP 25 sample should contain approximately $25 \%$ fewer non-hydrated cement grains than the reference samples. However, the observed difference was almost $53 \%$.

\section{Discussion}

Calorimetric measurement results support the assumption that cement grains in the RCP are potentially reactive and can be exposed through very fine grinding [30] and are therefore recommended for future investigations of the RCP properties.

The sharp shape of RCP particles negatively influences water demand and our results indicate that $\mathrm{w} / \mathrm{b}$ ratio increased as percentages of the RCP increased, which led to a higher shrinkage in the RCP samples than in the control samples. Additionally, because the
RCP is comprised of hydrated particles that have a lower density than cement particles and thus a lower modulus of elasticity, the RCP-containing samples exhibited greater shrinkage while drying. In future research, this negative effect might be reduced by introducing superplasticizers into mixtures [31] and improving the initial 2 day curing process (e.g. by covering molds with foil to reduce water evaporation).

A decrease of dynamic Young's and shear moduli for RCP samples was primarily caused by the lower density of old cement paste in the RCP and also impacted by higher water content. This caused the formation of higher numbers of pores in the RCPcontaining samples.

Our study illustrated that the substitution of cement with the RCP positively affected flexural strength for up to $15 \mathrm{wt} \%$ of the RCP. This increase in flexural strength is likely caused by a combination of the binder effect for non-hydrated cement grains (proven with hydration heat measurement, Figure 1) and the microfiller effect of old cement paste (achieved because of the milling process, Figure 2 as well as by the aggregate in the RCP, all of which contributed to 


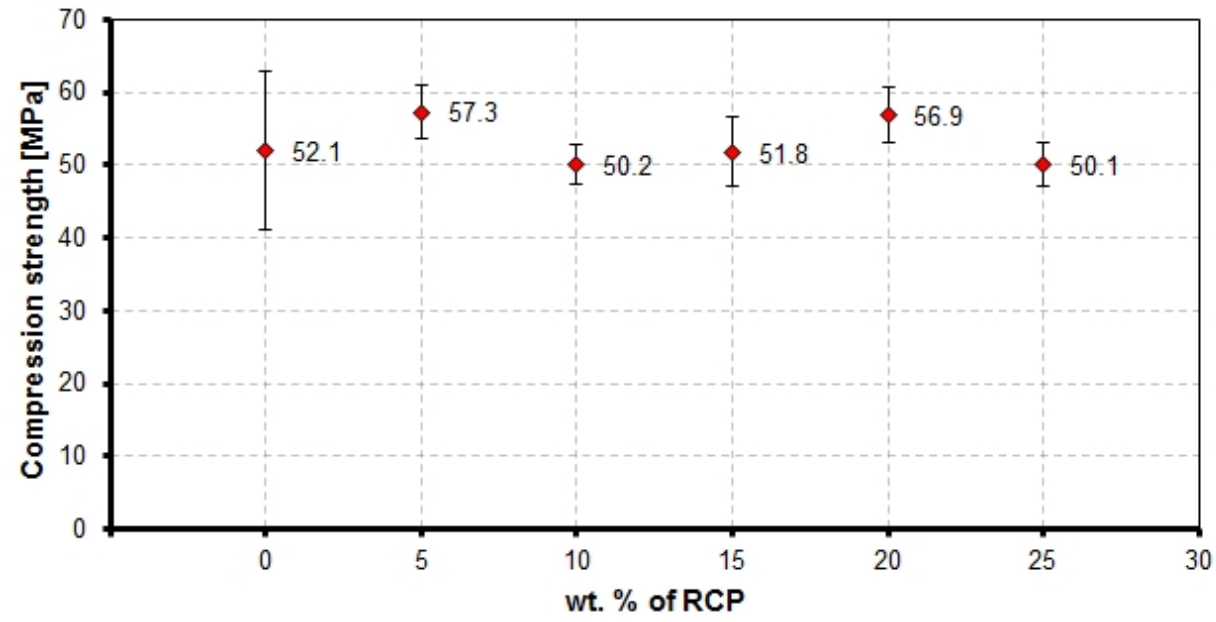

Figure 7. Compressive strength of samples with increasing RCP percentages.
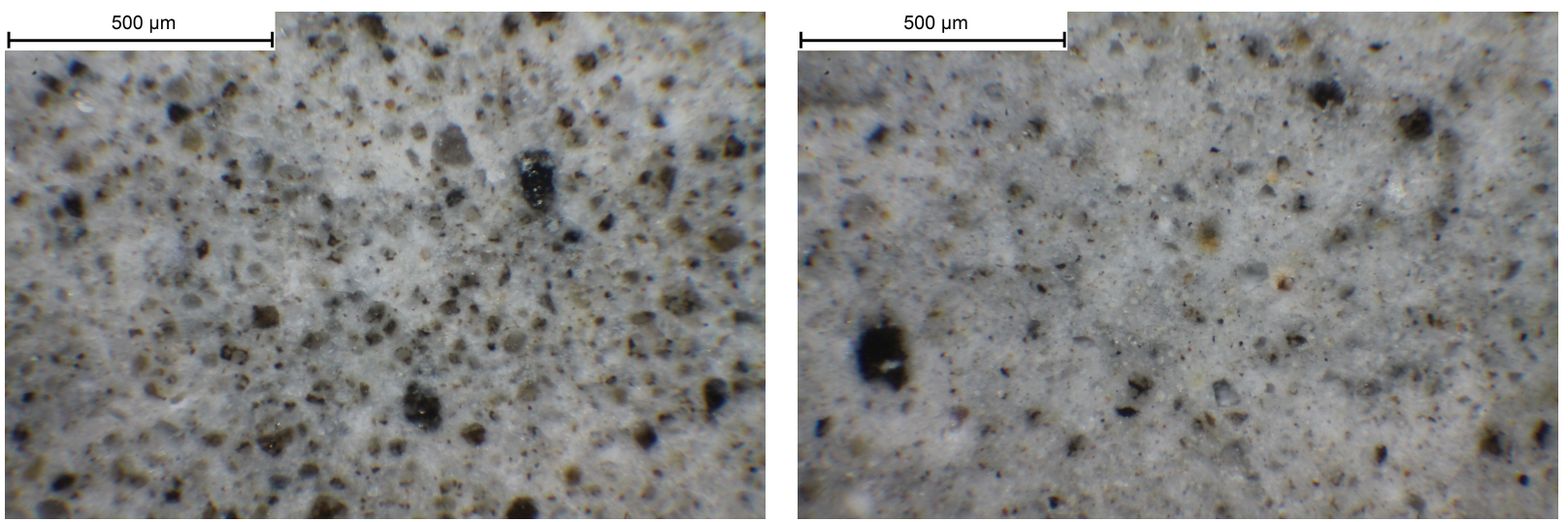

FiguRE 8. Optical microscopy images at $100 \times$ magnification of (left) reference sample and (right) sample with $25 \mathrm{wt} \%$ of the RCP.

a reduction in cohesiveness of the cement paste. It is presumed that higher percentages of the RCP in samples reduced flexural strength due to a weakening in the bonds between the RCP and cement particles as in the case of the transition zone between aggregates and cement in concrete.

Up to the level of $20 \mathrm{wt} \%$ of the RCP, compressive strength was increased and primarily affected by the RCP microfiller effect, which causes the filling of small pores with the fine particles of aggregates and old cement paste contained in the RCP and a slight binder effect.

Findings for flexural strength approximately match those in the prior research [30. But there was found an improvement in case of $10 \%$ to $20 \%$ amount of the RCP. Also, the influence of the RCP on compressive strength was similar to prior research 30.

On the microstructure images, the higher number of pores in RCP samples can be seen. The lower number of non-hydrated cement grains in RCP samples is visible on SEM images and likely caused by the fact that low density RCP did not hinder access of water to the cement grains and thus a larger amount of cement could hydrate when compared with the reference samples. However, this might have been the result of an inaccurate image analysis or statistic deviation. Lower differences in the number of non-hydrated cement grains can likely be expected in future studies including larger numbers of samples.

\section{Conclusions}

This paper examined the RCP as a cement replacement at levels of 5 to $25 \mathrm{wt} \%$, comparing results with a control sample and measuring properties and microstructures. Findings include:

- Cement paste with $50 \%$ cement and $50 \%$ old concrete milled at a similar level as cement produces higher hydration heat than cement alone, probably due to exposed non-hydrated cement grains.

- Partial replacement of cement with the RCP causes higher shrinkage than that observed for paste containing only cement (2 times in the case of $25 \mathrm{wt} \%$ of the RCP samples) due to RCP's lower density and resultant lower modulus of elasticity. This negative effect could likely be reduced by using superplasticizers and improving the curing process.

- A decrease of dynamic Young's and shear moduli for RCP samples (approximately $35 \%$ ) was primar- 

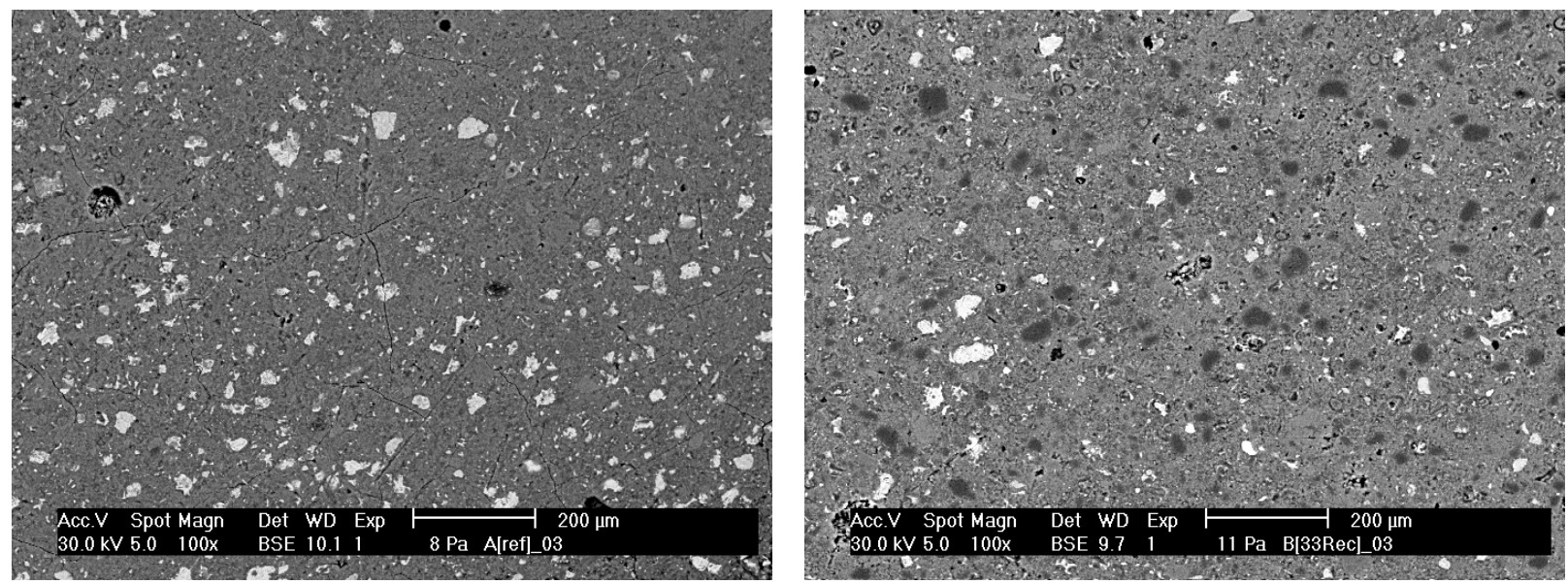

FiguRE 9. SEM images at $100 \times$ magnification of (left) reference sample and (right) sample with $25 \mathrm{wt} \%$ of the RCP.

ily caused by the lower density of old cement paste in the RCP and slightly impacted by higher water content. This led to the formation of a higher number of pores in samples containing RCP.

- For $15 \mathrm{wt} \%$ of the RCP, flexural strength increased by approximately $7 \%$. For $5 \mathrm{wt} \%$ RCP, compressive strength increased by approximately $10 \%$, likely due to its reactivity and microfiller properties.

\section{ACKNOWLEDGEMENTS}

The authors wish to express their gratitude to the Faculty of Civil Engineering, Czech Technical University (CTU) in Prague (SGS project SGS16/201/OHK1/3T/11 and TAČR project TA04031256) as well as the Center for Nanotechnology in Civil Engineering at the Faculty of Civil Engineering, CTU in Prague. The authors also thank to Czech National Library of Technology, Prague, namely to Stephanie Krueger.

\section{REFERENCES}

[1] J. R. Costes et al., Total recycling of concrete, 2007, http://omogine.blogspot.cz/2007/09/ full-concrete-recycling.html [2017-02-01]

[2] R. V. Silva et al., Properties and composition of recycled aggregates from construction and demolition waste suitable for concrete production. Construction and Building Materials 65 (2014), 201-217, DOI:10.1016/j.conbuildmat.2014.04.117

[3] D. Pedro et al., Influence of the use of recycled concrete aggregates from different sources on structural concrete. Construction and Building Materials 71 (2014), 141-151, DOI:10.1016/j.conbuildmat.2014.08.030

[4] C.-S. Poon et al., Effect of microstructure of ITZ on compressive strength of concrete prepared with recycled aggregates. The Hong Kong Polytechnic University, Hong Kong 2002, DOI:10.1016/j.conbuildmat.2004.03.005

[5] J. de Brito et al., Structural, material, mechanical and durability properties and behavior of recycled aggregates concrete. Journal of Building Engineering 6 (20116), 1-16, DOI:10.1016/j.jobe.2016.02.003
[6] L. Evangelista et al., Durability performance of concrete made with fine recycled concrete aggregates. Cement \& Concrete Composites 32 (2010), 9-14, DOI:10.1016/j.cemconcomp.2009.09.005

[7] M. Braga et al., Incorporation of fine concrete aggregates in mortars. Construction and Building Materials 36 (2012), 960-968, DOI:10.1016/j.conbuildmat.2012.06.031

[8] M. Pepe et al., Alternative processing procedures for recycled aggregates in structural concrete. Construction and Building Materials 69 (2014), 124-132, DOI:10.1016/j.conbuildmat.2014.06.084

[9] F. Tomosawa et al., Towards completely recyclable concrete. Integrated design and environmental issues in concrete technology. E \& FN Spon, London, UK (1996), 263-272.

[10] Z. Shui et al., Rehydration reactivity of recycled mortar from concrete waste experienced to thermal treatment. Construction and Building Materials 22 (2008), 1723-1729, DOI:10.1016/j.conbuildmat.2007.05.012

[11] Z. Shui Z et al., Cementitious characteristics of hydrated cement paste subjected to various dehydration temperatures. Construction and Building Materials 23 (2009), 531-537, DOI:10.1016/j.conbuildmat.2007.10.016

[12] Shui et al., Activation of fly ash with dehydrated cement paste. Aci Materials Journal 108 (2011), 108-112.

[13] M. V. A. Florea et al., Activation of liberated concrete fines and their application in mortars. Construction and Building Materials 50 (2014), 1-12, DOI:10.1016/j.conbuildmat.2013.09.012

[14] J. Shoon et al., Waste fibrecement: An interesting alternative raw material for a sustainable Portland clinker production. Construction and Building Materials 36 (2012), 391-403, DOI:10.1016/j.conbuildmat.2012.04.095

[15] J. Shoon et al., Fines extracted from recycled concrete as alternative raw material for Portland cement clinker production. Cement \& Concrete Composites 58 (2015), 70-80, DOI:10.1016/j.cemconcomp.2015.01.003 
[16] D. Gastaldi et al., An investigation on the recycling of hydrated cement from concrete demolition waste. Cement \& Concrete Composites 61 (2015), 29-35, DOI:10.1016/j.cemconcomp.2015.04.010

[17] E. Kwon et al., A study on development of recycled cement made from waste cementitious powder. Construction and Building Materials 83 (2015), 174-180, DOI:10.1016/j.conbuildmat.2015.02.086

[18] P. Wray et al., Straight talk with Karen Scrivener on cements, CO2 and sustainable development. American Ceramic Society Bulletin 91 (2012), 47-50.

[19] Ahmari et al., Production of geopolymeric binder from blended waste concrete powder and fly ash. Construction and Building Materials 35 (2012), 718-729, DOI:10.1016/j.conbuildmat.2012.04.04

[20] P.-C. Aïtcin, Vysokohodnotný beton. Informační centrum ČKAIT, Praha, červen 2005.

[21] Y. J. Kim et al., Utilization of waste concrete powder as a substitution material for cement. Construction and Building Materials 30 (2012) 500-504, DOI:10.1016/j.conbuildmat.2011.11.042

[22] M. Lidmila et al., Utilization of Recycled Fine-ground Concrete from Railway Sleepers for Production of Cement-based Binder. 51nd International Conference on Experimental Stress Analysis 2014, 323-326, DOI:10.4028/www.scientific.net/AMM.486.323

[23] M. Lidmila et al., Utilization of Recycled Binder for Improvement of Subsoil under Railway Sleepers. 51nd International Conference on Experimental Stress Analysis 2014.
[24] K. Šeps, I. Broukalová, Properties of cement based composite with fine ground recycled concrete. Advanced Materials Research 1000 (2014), 110-113, DOI:10.4028/www.scientific.net/AMR.1000.110

[25] Q. Liu et al., Investigation of using hybrid recycled powder from demolished concrete solids and clay bricks as a pozzolanic supplement for cement. Construction and Building Materials 73 (2014), 754-763, DOI:10.1016/j.conbuildmat.2014.09.066

[26] ASTM E1876-01 (2006). Standard Test Method for Dynamic Young's Modulus, Shear Modulus, and Poisson's Ratio by Impulse Excitation of Vibration.

[27] ČSN 73 1372: 2012. Nedestruktivní zkoušení betonu Rezonanční metoda zkoušení betonu.

[28] EN 12390-5: 2009. Testing hardened concrete - Part 5: Flexural strength of test specimens.

[29] EN 12390-3: 2009. Testing hardened concrete - Part 3: Compressive strength of test specimens.

[30] M. Lidmila, J. Topič et al., Mechanical Properties of Recycled Binder/Micro-Filler Cement-Based Material. Conference Special Concrete and Composites 2014, 234-237, DOI:10.4028/www.scientific.net/AMR.1054.234

[31] J. Topič et al., Shrinkage of the Cement with Different Amount of Finely Ground Recycled Concrete. International Journal of Advance Research in Science and EngineeringApplied Mechanics and Materials 4 (2015), 69-72, ISSN: 2319-8354.

[32] J. Topič et al., Replacement of Cement with Finely Ground Recycled Concrete: Influence on Mechanical Properties. Applied Mechanics and Materials 825 (2014), 69-72, DOI:10.4028/www.scientific.net/AMM.825.69 